\title{
Des sciences et des bibliothèques
}

\section{Christophe Didier}

\section{(2) OpenEdition}

Journals

Édition électronique

URL : https://journals.openedition.org/rbnu/1592

DOl : $10.4000 /$ rbnu. 1592

ISSN : 2679-6104

\section{Éditeur}

Bibliothèque nationale et universitaire de Strasbourg

\section{Édition imprimée}

Date de publication : 1 novembre 2014

Pagination : 7

ISBN : 9782859230548

ISSN : 2109-2761

\section{Référence électronique}

Christophe Didier, «Des sciences et des bibliothèques », La Revue de la BNU [En ligne], 10 | 2014, mis en ligne le 01 novembre 2014, consulté le 18 mai 2021. URL : http://journals.openedition.org/rbnu/ 1592 ; DOI : https://doi.org/10.4000/rbnu.1592

\section{(ब) $10(0$}

La Revue de la BNU est mise à disposition selon les termes de la Licence Creative Commons Attribution - Pas d'Utilisation Commerciale - Partage dans les Mêmes Conditions 4.0 International. 


\section{Des sciences et des bibliothèques}

Si la notion de " musée scientifique ", réactualisée lors des dernières décennies par l'appellation de " cités " (des sciences, de la mer, de l'espace, pour ne prendre que des exemples français) ou la création de "parcs à thèmes " aux buts pédagogiques ou récréatifs, est bien appréhendée du grand public comme des instances décisionnaires des mondes culturel, politique ou économique, celle de " bibliothèque scientifique " est incontestablement devenue plus floue, les " sciences dures ", comme on dit désormais, se nourrissant presque exclusivement de documentation en ligne à laquelle le chercheur a accès de son bureau ou de son laboratoire, le bibliothécaire voyant son rôle réduit à celui d'un " fournisseur d'accès ". La notion de bibliothèque scientifique serait donc en train de se vider de son sens... quand bien même les scientifiques continuent de fréquenter en nombre les bibliothèques - constat particulièrement frappant si l'on considère le monde étudiant.

En même temps, les efforts de vulgarisation de disciplines considérées comme ardues pour les non-initiés répondent à la demande d'un grand public désireux de pouvoir appréhender un monde contemporain vu comme de plus en plus soumis à une hyper-technicisation ; songeons aux problématiques écologiques ou médicales, elles qui relèvent aussi, dans le fond, des champs éthique, politique ou social mais dont la mise en œuvre est de plus en plus dépendante de technologies de pointe. À cette aune, l'histoire des sciences est elle aussi investie d'une mission pédagogique essentielle, permettant de remettre les questions actuelles en perspective et d'en expliquer le long cheminement intellectuel. Si donc la recherche semble avoir déserté les bibliothèques comme lieux physiques, l'étude et le loisir en garnissent les rayons et assurent à ces mêmes lieux une fréquentation qui, elle, ne se dément pas.

De ce point de vue, les bibliothèques scientifiques " traditionnelles ", celles qui reposent sur l'accumulation de documentation manuscrite ou imprimée, gardent tout leur sens, mais se transforment lentement en bibliothèques historiques, et non plus en instruments de la science en marche. Peut-être faut-il voir dans cette évo- lution les difficultés de positionnement qu'éprouvent depuis quelques décennies les expositions universelles (ces autres "bras armés ", jusqu'au milieu du $20^{\mathrm{e}}$ siècle, des sciences et techniques triomphantes), ni vraiment musées, ni vraiment laboratoires - et donc devenues inaptes, dans leur aspect purement événementiel, à parler au monde de la recherche comme à la société des loisirs.

Parler des sciences et des bibliothèques est donc faire le constat d'une relation en pleine mutation. Voici en tout cas un thème qui ne messied pas à la revue d'une bibliothèque qui s'apprête à réouvrir au public son bâtiment historique totalement métamorphosé - à une époque où les bibliothèques des universités scientifiques se posent, de façon globale, des questions de fond quant à leur essence et à leur destination. Ce numéro a d'ailleurs été pensé en étroite collaboration avec Edouard Mehl, philosophe et historien des sciences, qui était jusqu'à cet été (et son départ pour Lille) vice-président de l'Université de Strasbourg, chargé des " sciences en société " - donc au croisement des diverses problématiques évoquées dans cet éditorial, et dont les articles du dossier se font, chacun à leur manière, l'écho. Si la question de savoir ce qu'est une " bibliothèque scientifique " aujourd'hui reste ouverte (Christian Jacob en énumère tous les enjeux dans les pages qui suivent), celle de la relation des sciences et des bibliothèques est un objet d'études qui n'a pas fini de stimuler la recherche, y compris (surtout ?) dans les relations complexes qu'entretiennent entre elles sciences " dures " et sciences humaines et sociales - voire sciences et arts ; à cet égard, la figure d'Abraham Moles (dont la bibliothèque personnelle rejoindra sous peu les fonds de la BNU) en est un exemple particulièrement évocateur, lui qui était à l'écoute des transformations à l'œuvre dans ce qu'il a nommé la " psychologie sociale " et qui, venu du monde des sciences, a su investir d'autres champs de recherche, suivant le phénomène d'irrigation d'un schéma de pensée par un autre qui est à la base de maint cheminement intellectuel - osera-t-on dire de mainte étape de la pensée scientifique?

\section{Christophe Didier}

